\title{
Arterial Spin Labeling and Blood Oxygen Level-Dependent MRI Cerebrovascular Reactivity in Cerebrovascular Disease: A Systematic Review and Meta-Analysis
}

\author{
Diederik P.J. Smeeing ${ }^{\mathrm{a}} \quad$ Jeroen Hendrikse ${ }^{\mathrm{a}}$ Esben T. Petersen ${ }^{\mathrm{a}} \mathrm{b}$ \\ Manus J. Donahue ${ }^{c}$ Jill B. de Vis ${ }^{a}$ \\ a Department of Radiology, University Medical Center Utrecht, Utrecht, The Netherlands; ${ }^{b}$ Danish Research Centre \\ for Magnetic Resonance, Hvidovre Hospital, Hvidovre, Denmark; ${ }^{\circ}$ Department of Radiology and Radiological \\ Sciences, Vanderbilt University School of Medicine, Nashville, Tenn., USA
}

\section{Key Words}

Blood oxygen level-dependent $\cdot$ Arterial spin labeling $\cdot$ MRI . Cerebrovascular reserve capacity $\cdot$ Reactivity $\cdot$ Cerebral hemodynamics

\begin{abstract}
Background: The cerebrovascular reactivity (CVR) results of blood oxygen level-dependent (BOLD) and arterial spin labeling (ASL) MRI studies performed in patients with cerebrovascular disease (steno-occlusive vascular disease or stroke) were systematically reviewed. Summary: Thirty-one articles were included. Twenty-three (74.2\%) studies used BOLD MRI to evaluate the CVR, 4 (12.9\%) studies used ASL MRI and 4 (12.9\%) studies used both BOLD and ASL MRI. Thirteen studies (3 significant) found a lower BOLD CVR, 2 studies found a similar CVR and 3 studies found a higher CVR in the ipsilateral compared to the contralateral hemisphere. Nine (5 significant) out of 10 studies found a lower BOLD CVR in the ipsilateral hemispheres of patients compared to controls. Six studies (2 significant) found a lower ASL CVR in the ipsilateral compared to the contralateral hemispheres. Three out of 5 studies found a significant lower ASL CVR in the ipsilat-
\end{abstract}

\section{KARGER}

E-Mail karger@karger.com www.karger.com/ced

\section{() 2016 The Author(s) \\ Published by S. Karger AG, Basel 1015-9770/16/0424-0288 \$39.50/0}

This article is licensed under the Creative Commons AttributionNonCommercial-NoDerivatives 4.0 International License (CC BYNC-ND) (http://www.karger.com/Services/OpenAccessLicense). Usage and distribution for commercial purposes as well as any distribution of modified material requires written permission. eral hemispheres of patients compared to controls. Key Messages: This review brings support for a reduced BOLD and ASL CVR in the ipsilateral hemisphere of patients with cerebrovascular disease. We suggest that future studies will be performed in a uniform way so reference values can be established and could be used to guide treatment decisions in patients with cerebrovascular disease.

(c) 2016 The Author(s)

Published by S. Karger AG, Basel

\section{Introduction}

Cerebrovascular reactivity (CVR) can be defined as the capacity of blood vasculature to increase cerebral perfusion through vasodilatation to meet the energy requirements of the brain tissue [1]. The CVR gives an indication as to how close the brain is to the exhaustion of the reserve capacity, and therefore may have prognostic potential for portending stroke risk and/or guiding treatment decisions [2-4]. Decreased regional CVR has been suggested to be an independent predictor of 5-year stroke risk [3]. Also, it has been shown that patients, with steno-occlu- 
sive cerebrovascular disease and a decreased CVR have a $35 \%$ risk of developing an ischemic stroke, while patients with a normal CVR only have an $11 \%$ risk [3]. In patients with moyamoya disease (MMD) and decreased CVR, a surgical anastomosis may improve the long-term prognosis by improving cerebral hemodynamics [2]. Furthermore, the CVR can be used to identify patients eligible for carotid endarterectomy [4]. Positron emission tomography (PET), single-photon emission CT (SPECT) and transcranial Doppler ultrasonography (TCD) have always been the golden standard for the assessment of the CVR. More recently, alternative, noninvasive methods like blood oxygen level-dependent (BOLD) MRI and arterial spin labelling (ASL) MRI have been developed to evaluate the CVR. Both BOLD and ASL MRI have demonstrated great potential to evaluate the CVR $[5,6]$. However, due to the large amount of studies that have been performed in different patient groups and with different imaging sequences and post-processing algorithms, it is currently unclear if there is a consistent difference in BOLD and ASL CVR between patients with cerebrovascular disease and healthy control subjects. Additionally, literature has not settled upon CVR thresholds for tissue at risk and a proper universally defined way to express CVR is still lacking; for example, CVR can be presented in $\% \mathrm{BOLD}, \% \mathrm{BOLD} / \mathrm{mm} \mathrm{Hg}$, \% cerebral blood flow $(\mathrm{CBF}) / \mathrm{mm} \mathrm{Hg}$ and $\triangle \mathrm{CBF}$. Therefore, BOLD and ASL MRI can currently not be used as prognosticators for stroke risk. The main aim of the current systematic review was therefore to describe and to interpret the CVR results of ASL and BOLD MRI studies performed in patients with steno-occlusive cerebrovascular disease or stroke. The second goal of this study was to try to provide reference CVR values for both normal and abnormal perfused brain tissue.

\section{Background}

\section{Vasodilatory Challenges}

Different techniques are used to cause a vasodilatory challenge and therefore an increase in CBF and cerebral blood volume (CBV), which is consequently used to determine the CVR [7]. A first approach is to modulate a subject's $\mathrm{PaCO}_{2}$, thereby inducing an increase in tissue perfusion through vasodilatation of the cerebral vasculature. For this, either hypercarbic gas administration (in combination with atmospheric air) or carbogen (hypercarbic hyperoxia) are used [8]. More simply, subjects could just be told to hold their breath increasing the
$\mathrm{PaCO}_{2}$ and therefore the CBF. A second approach is the administration of acetazolamide (ACZ), a carbonic anhydrase inhibitor. Inhibition of carbonic anhydrase causes carbonic acidosis, which induces a considerable increase in CBF [9]. The third commonly used approach is to induce a functional task, which increases the blood flow toward a specific region.

\section{PET Imaging, SPECT Imaging and Transcranial \\ Doppler Ultrasonography}

PET and SPECT have always been the brain imaging standard for the assessment of the CVR. In both methods, the CVR is measured by means of a vasodilatory challenge. Unfortunately, both PET and SPECT are invasive, as they make use of ionizing radiation, and in the case of 15-O PET, an onsite cyclotron is required. Therefore, they are less suited for clinical use in nonspecialized centers [10].

TCD is noninvasive technique that has the goal to assess hypercapnia-mediated changes in $\mathrm{CBF}$ at the level of the brain feeding vessels [11]. To enable this, changes in measured peak blood velocity from baseline to hypercapnia are transformed to changes in $\mathrm{CBF}$, and from these the $\mathrm{CBF}$ reactivity is estimated [12]. A disadvantage of TCD is that it does not assess CVR at the brain tissue level and that it assumes that the insonated arterial diameter remains stable throughout hypercapnia [13]. In addition, some other factors, for example, blood pressure, influence the reliability of CBF measurements [14].

\section{$B O L D$ and $A S L M R I$}

BOLD and arterial spin labeling (ASL) MRI are noninvasive and provide information on the status of brain parenchyma [15]. CVR values measured by BOLD or ASL MRI were shown to correlate with SPECT values $[16,17]$.

BOLD MRI measures changes in the T2* of blood and tissue water secondary to decreases in the amount of venous capillary and venule deoxyhemoglobin $(\mathrm{dHb})$ [18]. Specifically, in case of BOLD CVR measurements, a vasodilatory challenge increases $\mathrm{CBF}$ and $\mathrm{CBV}$ in the brain parenchyma while inducing a much smaller change in metabolism. As such, information regarding CVR can be inferred from the $\mathrm{dHb}$ reductions in and around veins.

Contrary to BOLD measurements that are related to a combination of $\mathrm{CBF}, \mathrm{CBV}$, and oxygen consumptions, ASL MRI measures the CBF solely and quantitatively. This is achieved by magnetically labeling the arterial blood water protons at the level of the brain-feeding ves- 


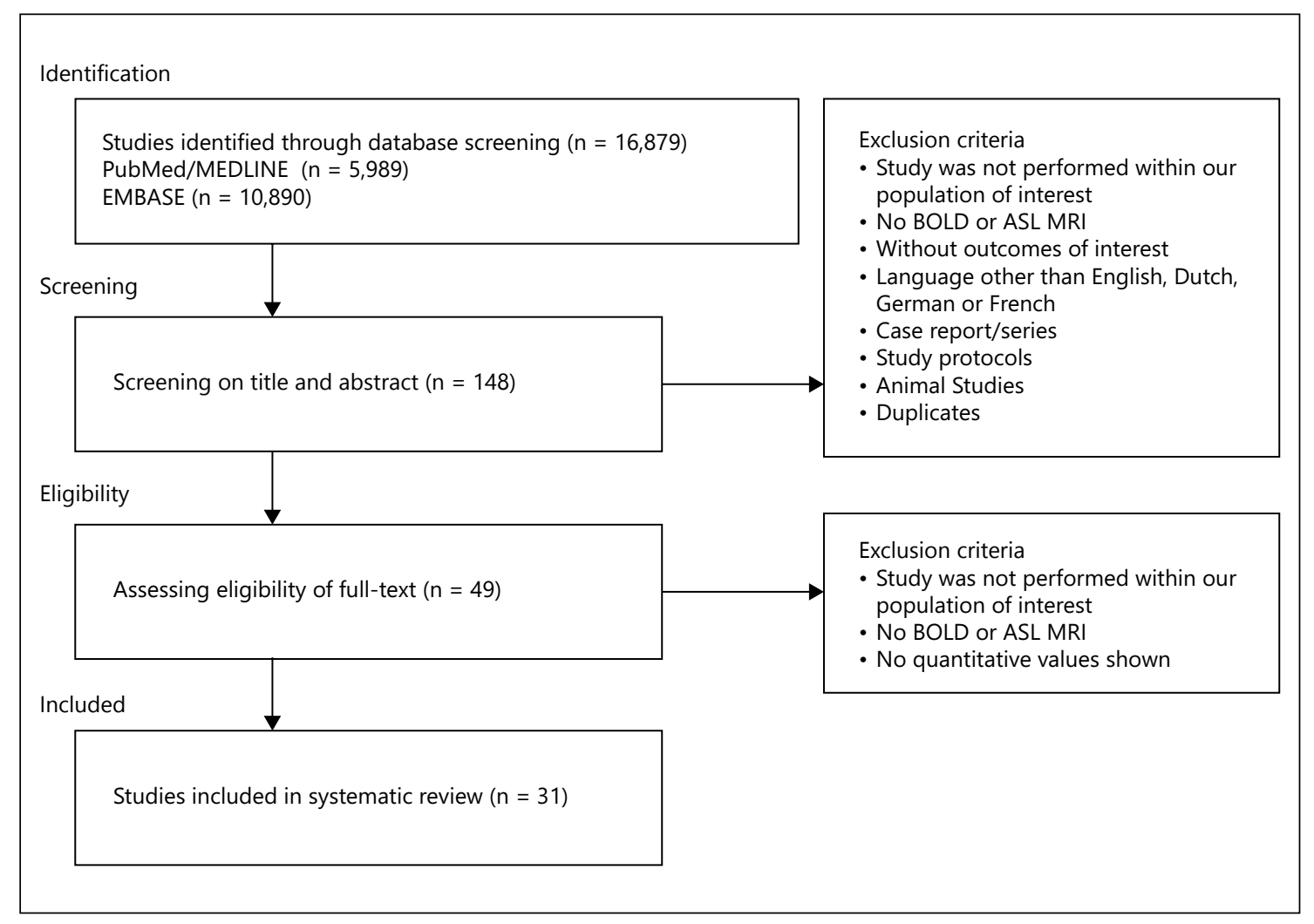

Fig. 1. Process from initial search to final inclusions for studies on cerebrovascular reserve capacity using ASL or BOLD MRI.

sels. These labeled blood protons then travel upstream through the blood vessels and exchange with tissue water protons. At this point in time, a 'labeled image' is made, which is subtracted from a nonlabeled 'control image' to obtain a perfusion-weighted image. $\mathrm{CBF}$ can be quantified in absolute units (e.g. $\mathrm{ml}$ blood/100 g tissue/min) upon application of appropriate kinetic models. Similar to BOLD MRI, a vasodilatory challenge is added to obtain the CVR.

\section{Methods}

No ethical committee approval was deemed necessary to conduct this literature review.

\section{Search Strategy and Selection Criteria}

To be eligible for inclusion in this systematic review, published articles had to concern ASL- and/or BOLD reactivity studies performed in patients with cerebrovascular steno-occlusive disease or stroke. In October 2015, 2 authors (D.P.J.S. and J.B.V.) performed an electronic based search using the PubMed/MEDLINE and Embase database. The search was performed using the following search terms: (cerebrovascular disorders OR stroke OR occlusion
OR stenosis OR ischemia) AND (ASL OR BOLD OR blood flow) AND (magnetic resonance imaging OR MRI OR MR). Letters, comments, abstracts for conferences, case reports, studies that included $\leq 3$ participants, studies including children, animal studies and articles written in languages other than English, Dutch, German or French were excluded. Also, articles had to present quantitative study results to be eligible for inclusion. No further restrictions were made. Articles were screened and duplicates were removed. Figure 1 shows a flowchart of the search using the PRISMA statement [19].

\section{Quality Assessment}

The methodological quality of all included studies was assessed using an adjusted version of a recent review on delayed cerebral ischemia [20]. Studies were assessed on design, aim, population selection, study size and outcome presentation (table 1). Studies were predefined as high quality with a score of 6 , as intermediate quality with a score of 4 or 5 and as a low quality with a score of 3 or less.

\section{Data Extraction}

The following data were extracted from the studies: first author, year of publication, study design, the country in which the study was performed, imaging modality (ASL and/or BOLD), MRI field strength, the type of cerebrovascular disease (occlusion, stenosis, stroke or MMD), the affected vessel, number of patients (male/ 
Table 1. Quality assessment

\begin{tabular}{|c|c|c|c|c|c|c|}
\hline \multirow[t]{2}{*}{ Publication } & \multicolumn{5}{|c|}{ Quality criteria } & \multirow{2}{*}{$\begin{array}{l}\text { Total } \\
\text { points }\end{array}$} \\
\hline & design $^{a}$ & population $^{\mathrm{b}}$ & $\operatorname{aim}^{c}$ & $\operatorname{size}^{\mathrm{d}}$ & $\begin{array}{l}\text { outcome } \\
\text { presentation }^{\mathrm{e}}\end{array}$ & \\
\hline Altamura et al. [21] & 2 & 1 & 1 & 0 & 1 & 5 \\
\hline An et al. [36] & 2 & 1 & 1 & 0 & 0 & 4 \\
\hline Amemiya et al. [22] & 2 & 1 & 1 & 1 & 1 & 6 \\
\hline Blicher et al. [37] & 2 & 1 & 1 & 0 & 1 & 5 \\
\hline Bokkers et al. [23] & 2 & 1 & 1 & 0 & 1 & 5 \\
\hline Bokkers et al. [24] & 2 & 1 & 1 & 0 & 1 & 5 \\
\hline Bonakdarpour et al. [38] & 2 & 1 & 1 & 0 & 1 & 5 \\
\hline Bouvier et al. [39] & 2 & 1 & 1 & 0 & 1 & 5 \\
\hline Carusone et al. [25] & 2 & 1 & 1 & 0 & 1 & 5 \\
\hline Donahue et al. [7] & 2 & 1 & 1 & 1 & 0 & 5 \\
\hline Donahue et al. [26] & 1 & 1 & 1 & 0 & 1 & 4 \\
\hline Faraco et al. [41] & 2 & 1 & 1 & 0 & 0 & 4 \\
\hline Geranmayeh et al. [42] & 2 & 1 & 1 & 1 & 1 & 6 \\
\hline Goode et al. [27] & 2 & 1 & 1 & 0 & 1 & 5 \\
\hline Haller et al. [28] & 2 & 1 & 1 & 0 & 1 & 5 \\
\hline Heyn et al. [29] & 1 & 1 & 1 & 0 & 1 & 4 \\
\hline Jensen et al. [30] & 2 & 1 & 1 & 0 & 0 & 4 \\
\hline Lythgoe et al. [31] & 2 & 1 & 1 & 0 & 1 & 5 \\
\hline MacIntosh et al. [43] & 2 & 1 & 1 & 0 & 1 & 5 \\
\hline Mandell et al. [32] & 2 & 1 & 1 & 1 & 1 & 6 \\
\hline Manganotti et al. [44] & 2 & 1 & 1 & 0 & 0 & 4 \\
\hline Mazzetto-Betti et al. [33] & 2 & 1 & 1 & 0 & 1 & 5 \\
\hline Murata et al. [45] & 2 & 1 & 1 & 0 & 0 & 4 \\
\hline Pineiro et al. [34] & 2 & 1 & 1 & 0 & 1 & 5 \\
\hline Sam et al. [46] & 1 & 1 & 1 & 0 & 1 & 4 \\
\hline Sam et al. [5] & 1 & 1 & 1 & 1 & 1 & 5 \\
\hline Schaaf et al. [35] & 2 & 1 & 1 & 0 & 1 & 5 \\
\hline Shiino et al. [16] & 2 & 1 & 1 & 0 & 1 & 5 \\
\hline Uchihashi et al. [17] & 2 & 1 & 1 & 0 & 1 & 5 \\
\hline De Vis et al. [40] & 2 & 1 & 1 & 0 & 1 & 5 \\
\hline Zhao et al. [6] & 2 & 1 & 1 & 1 & 1 & 6 \\
\hline
\end{tabular}

a Prospective cohort (2), retrospective cohort (1), or unclear $(0) ;{ }^{b}$ included population is clearly described (1), included population is not clearly described (0); ${ }^{c}$ the aim is clearly described (1), the aim is not clearly described (0); ${ }^{\mathrm{d}}$ number of patients was $\geq 25$ (1), number of patients was $<25(0)$; ${ }^{\mathrm{e}}$ mean or median numbers of percentage signal change are provided with a $95 \%$ CI or p value (1), mean or median numbers of percentage signal change are not provided or without a $95 \% \mathrm{CI}$ or $\mathrm{p}$ value (0).

female), patients characteristics (age and gender), number of controls and their characteristics, type and dose of challenge used (breath holding, carbon dioxide inhalation, ACZ (Diamox) or functional task), the evaluated region, the results of the hemisphere ipsilateral to the affected artery, the results of the contralateral hemisphere if available, and the results of the control group if available.

\section{Data Analysis}

The data of all included studies were presented systematically in tables and figures. To overcome the lack of a proper universally defined CVR definition, all CVR data were converted to the same units if possible; for example, all $\mathrm{CO}_{2}$ study results were converted to percent signal change per change of $10 \mathrm{~mm} \mathrm{Hg}$ in endtidal $\mathrm{CO}_{2}$. In case mean values, $\mathrm{SDs}$ or $\mathrm{p}$ values were not shown in the article, statistical analysis was performed to obtain these values (MedCalc $^{\circledR}$ version 13.3.1.0, MedCalc Software bvba, Ostend, Belgium). Student $t$ tests were performed to compare ipsilateral vs. contralateral hemispheres, and ipsilateral vs. control hemispheres. Subgroup analyses were performed to evaluate CVR in the different subgroups (occlusion, stenosis, stroke, MMD or mixed disease). These latter analyses were performed using Review Manager (RevMan) software (computer program), version 5.3. Copenhagen: The Nordic Cochrane Centre, The Cochrane 
Collaboration, 2014). Mean differences (MD) with 95\% CI were calculated using the inverse variance method with a random effects model. Statistical heterogeneity was examined using the $\mathrm{Tau}^{2}$ test, the chi-square test, the degrees of freedom, the $\mathrm{I}^{2}$ statistic and the overall effect $\mathrm{Z}$ test.

\section{Results}

\section{Search}

The flowchart of the study selection process is illustrated in figure 1. The search in PubMed/MEDLINE identified 5,989 articles, and the search in Embase identified 10,890 articles. After screening, removing duplicate articles and assessing full-text articles, we found a total of 31 articles eligible for inclusion [5-7, 16, 17, 21-46]. Articles about moyamoya patients were included only if lateralizing disease was present in them. Lateralizing disease was defined as symptoms being more related to one hemisphere than to the other one.

\section{Quality Assessment}

A total of 4 studies were assessed as having a high quality. All other studies had an intermediate quality score (table 1). Most studies had an intermediate score due to a low score on the number of included patients. In only 6 (19.4\%) studies, 25 or more patients were included. All studies had clearly described inclusion and exclusion criteria and had a clear research question.

\section{Baseline Characteristics}

The characteristics of all included studies are described in table 2. The publication date of the articles ranged from 1999 until 2015. All studies were published in English. Of the total 31 included studies, 27 (87.1\%) were prospective and $4(12.9 \%)$ were retrospective studies. The studies included a total of 600 patients ( $60 \%$ men). The study sample size ranged from 3 to 60 patients with a mean of 19 patients. Twenty-three (74.2\%) studies used BOLD MRI to evaluate the CVR, 4 (12.9\%) studies used ASL MRI, and $4(12.9 \%)$ studies used both BOLD and ASL MRI. A 3 tesla scanner was used in $22(71.0 \%)$ studies, a 1.5 tesla MRI system in $8(25.8 \%)$ studies, and in one study, the MRI field strength was not reported. Two studies were performed in patients with occlusion of one or more of the brain feeding arteries, 9 studies were performed in patients with stenosis of the brain feeding arteries, 8 studies were performed in stroke patients, 2 studies were performed in patients with MMD, and 10 studies included patients of several of the above-mentioned categories (mixed disease). In case of stenosis of the brain feeding arteries, the percentage of stenosis was provided when given in the article (table 2 ).

\section{Data Extraction}

Different challenges were used to provoke a vascular response and as such to obtain a reactivity measurement; in 15 studies, a breathing challenge was performed; in 10 studies, a functional task was executed; in 3 studies, ACZ was administered; and in 3 studies, an external stimulation was applied (table 2). Studies were performed at different time windows, and this is especially of importance in studies investigating stroke patients. In these particular studies, 3 studies investigated CVR in the acute phase, 1 study investigated the CVR in the subacute phase, 5 studies investigated the CVR in the chronic phase and 2 studies performed CVR measurements at different time intervals. A few studies presented more than just one study result. From these studies, we only demonstrated the measurements that were deemed most relevant for our study purpose. In the study of Pineiro et al. [34], the results of the right-hand movements were used because more data of these were presented than for the left-hand movements. In the study of Heyn et al. [29], the results of patients with pial collaterals were used. In the study of Donahue et al. [26], the results of the hemispheres $(n=7)$ with the highest disease categorization, as quantified from the modified Suzuki score, were used [47].

\section{BOLD and ASL Study Results}

Example ASL and BOLD images are shown in figures 2 and 3. Figure 2 shows the images of a patient with an occlusion of both internal carotid arteries who presented with asymmetric disease on the ASL CBF, ASL CVR and BOLD CVR images. Figure 3a shows mean BOLD CVR images of 50 patients with MMD. Figure $3 \mathrm{~b}$ shows BOLD CVR images of a patient pre- and post-surgery.

The reactivity results of the studies that measured percentage ASL or BOLD signal change are shown for each subgroup of patients in table 3 , and are presented in figures 4 and 5 . The reactivity results of 6 studies, which evaluated the results using an asymmetry index, the number of activated voxels or calculated z-statistics, are shown in table 4.

Figure 4 shows the BOLD CVR results in a bar plot of the 21 studies, which presented a percentage signal change. The values shown in this bar plot are presented in table 3. Thirteen studies found a lower CVR in the ipsilateral compared to the contralateral hemisphere $[5,25$, $26,28,29,31,33,35,38-40,43,46]$. Three of these 13 


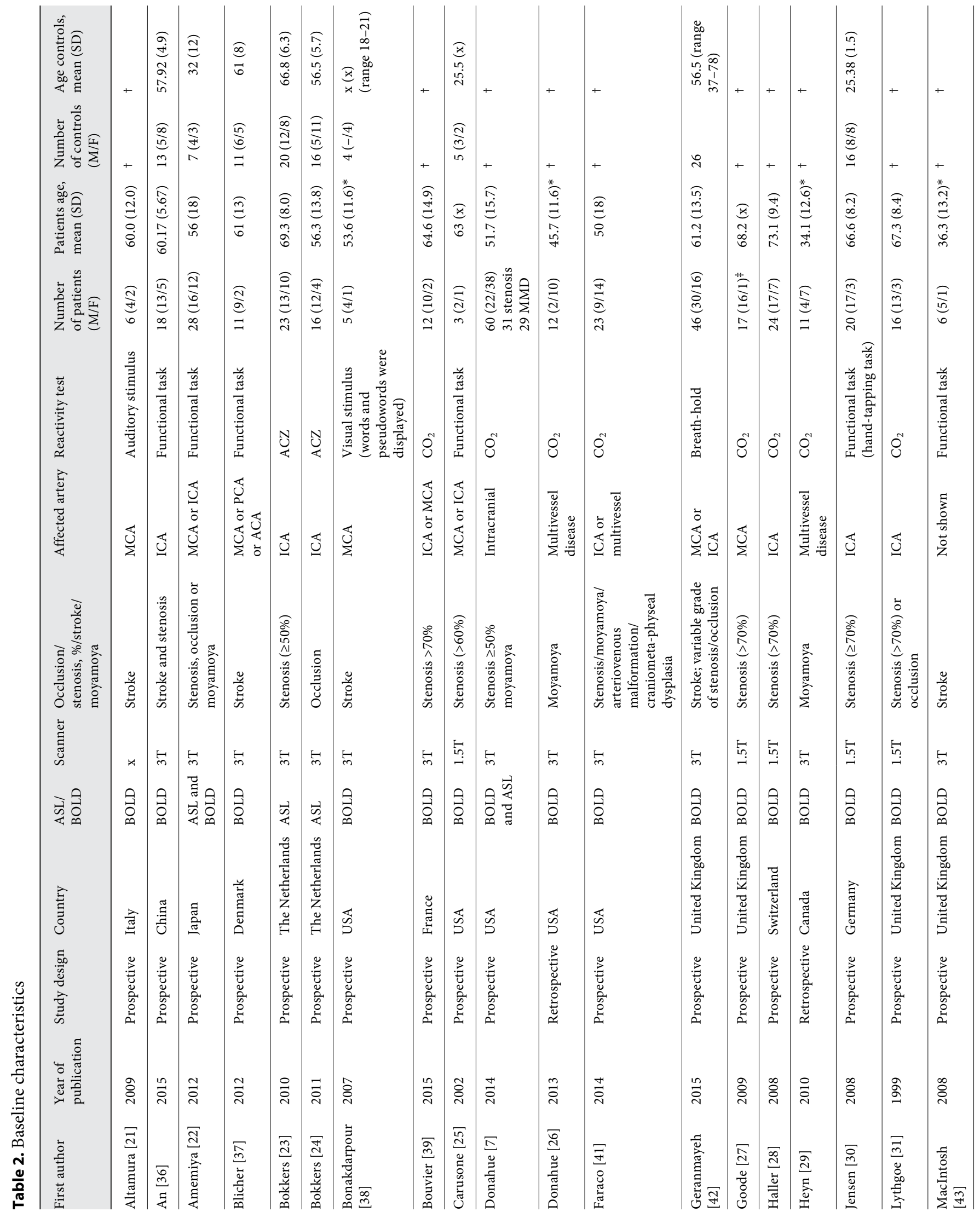




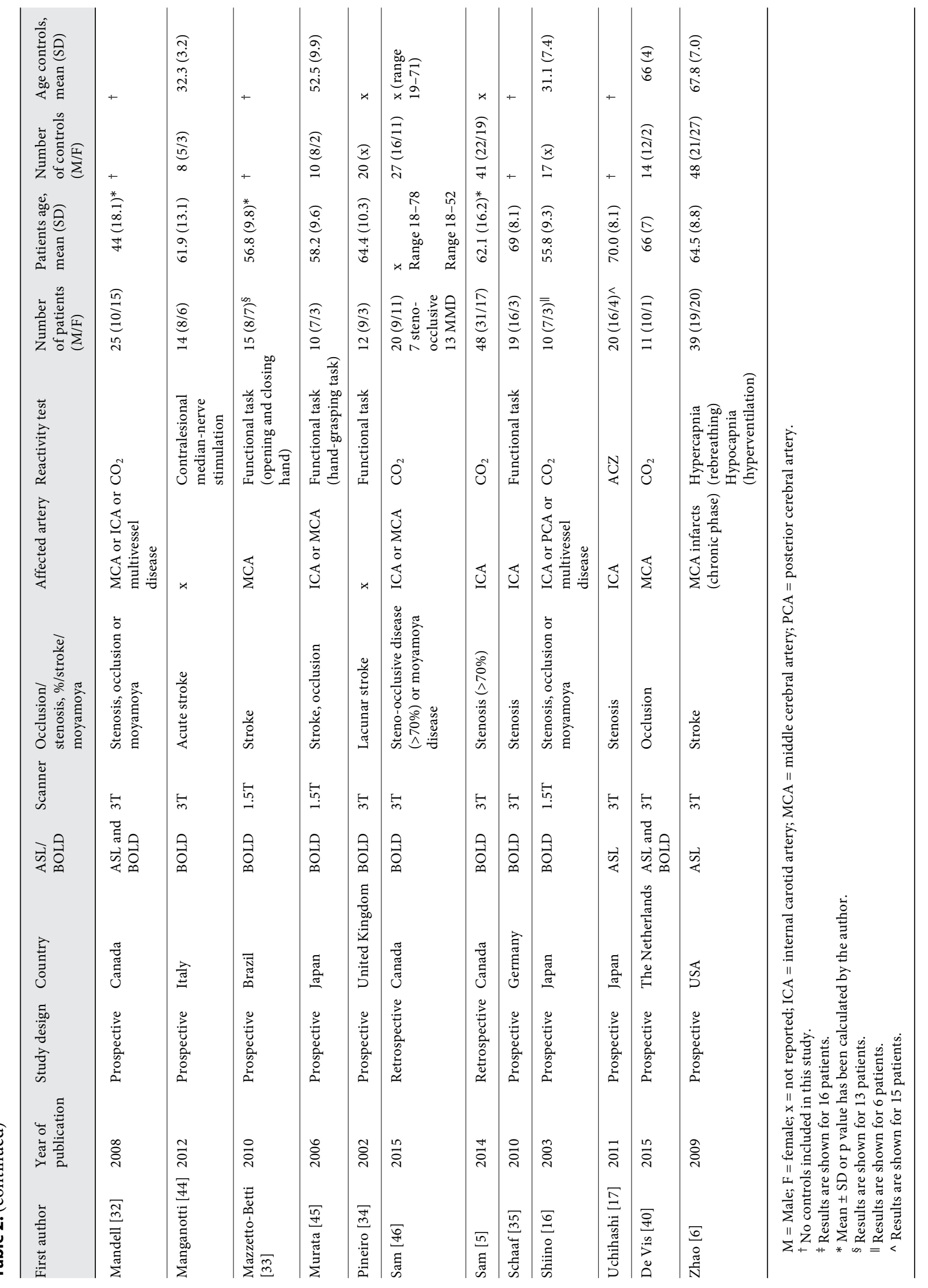




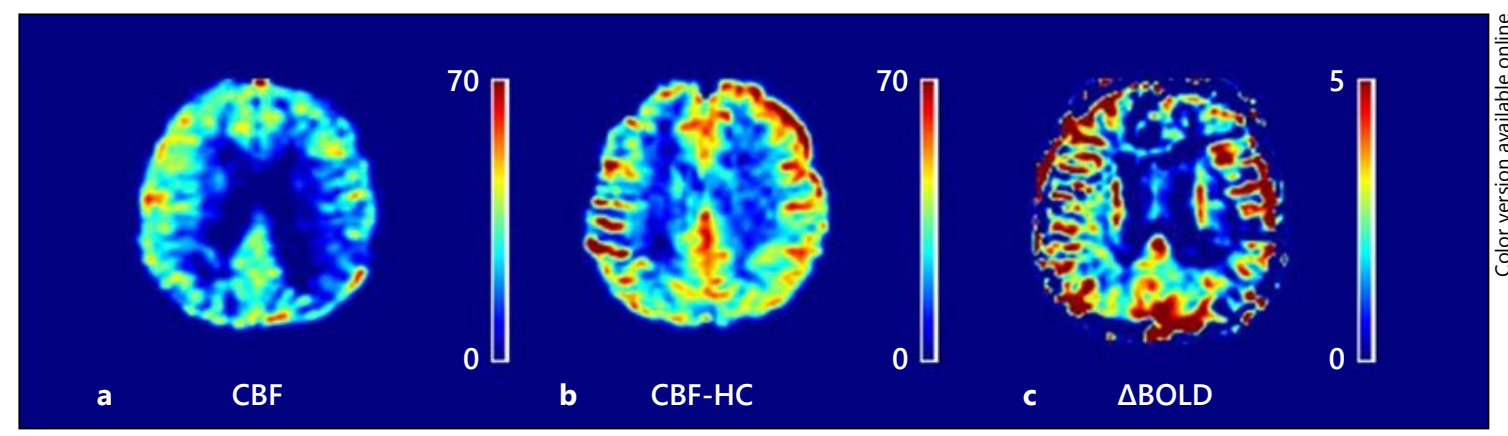

Fig. 2. ASL and BOLD MRI images. ASL CBF image (a), ASL CVR image (b), and BOLD CVR image (c) of a 70-year-old male patient with occlusion of both internal carotid arteries. Asymmetric disease with lower ASL CBF, ASL CVR and BOLD CVR in the right hemisphere compared to the left. Right hemisphere: ASL CBF: 41 $\mathrm{ml} / 100 \mathrm{~g} / \mathrm{min}$, ASL CVR: $67 \mathrm{ml} / 100 \mathrm{~g} / \mathrm{min}$, BOLD CVR: 3.0\% signal change. Left hemisphere: ASL CBF: $24 \mathrm{ml} / 100 \mathrm{~g} / \mathrm{min}$, ASL CVR: $81 \mathrm{ml} / 100 \mathrm{~g} / \mathrm{min}$, BOLD CVR: $2.2 \%$ signal change.

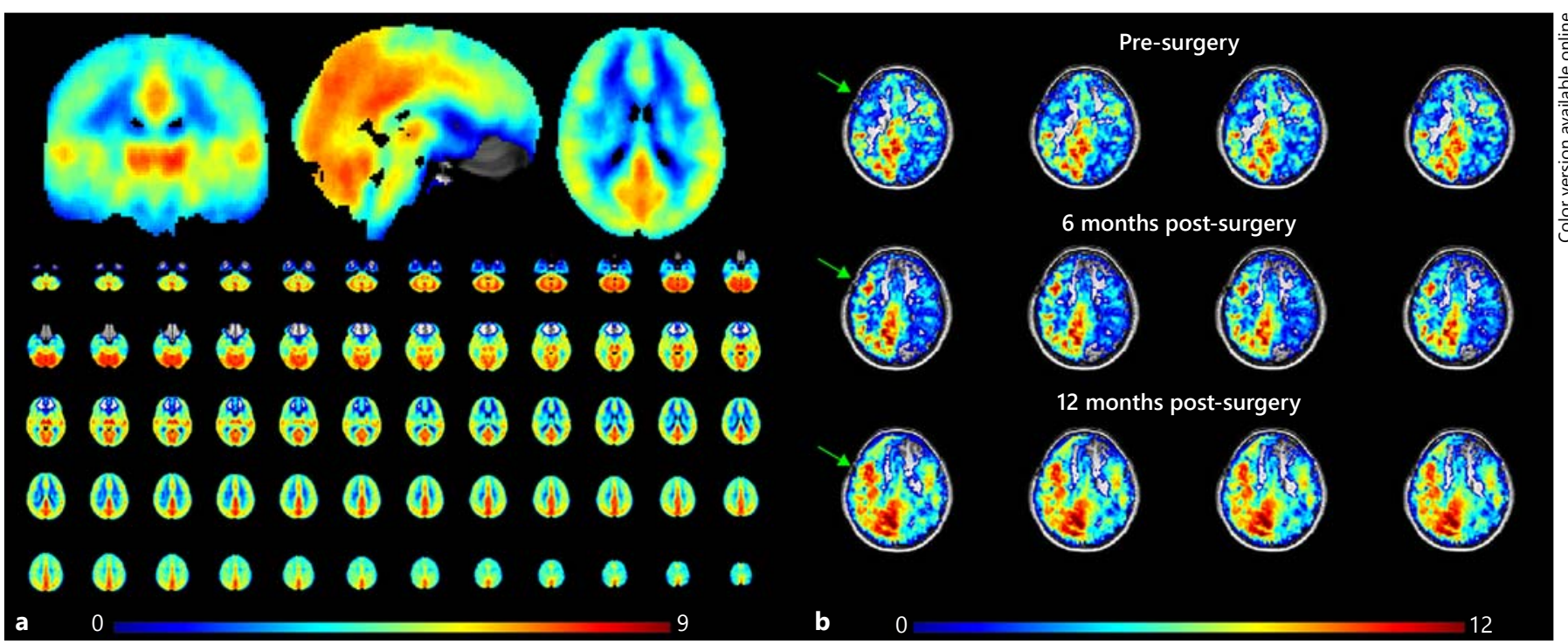

Fig. 3. BOLD MRI images of moyamoya patients. a Mean BOLD CVR maps of 50 patients with MMD. b Patient with bilateral MMD. Upper row, BOLD CVR images pre-surgery. Middle row, BOLD CVR images made 6 months after encephaloduroarterio- synangiosis procedure. Lower row, BOLD CVR images made 12 months after surgery. An increase in BOLD CVR from pre-surgery to 6 and 12 months post-surgery can be appreciated. studies found significant differences [5, 28, 33]. Two studies showed similar results in the ipsilateral and contralateral hemispheres [27, 42]. Three studies showed a higher CVR in the ipsilateral compared to the contralateral hemispheres; none of these 3 studies found a significant result $[21,32,34]$. The residual 3 studies did not show the results of either the ipsilateral or the contralateral hemisphere. In 10 of the BOLD CVR studies, a healthy control group was included $[5,16,22,25,34,37,38,40$, $42,46]$. Nine of these 10 studies showed a lower CVR in the ipsilateral hemispheres of the patients compared to the CVR measured in the healthy controls, and 5 of these 9 studies found significant differences [5, 22, 34, 40, 42]. Noteworthy to the reader is that the low \%BOLD CVR in Donahue et al. [26] and Geranmayeh et al. [42] is caused by the normalization of the \%BOLD CVR changes by the end-tidal $\mathrm{CO}_{2}$.

Figure 5 shows the results of the 7 studies in which ASL MRI was used and the percentage signal change is presented in this figure. Six studies found a lower CVR in the 


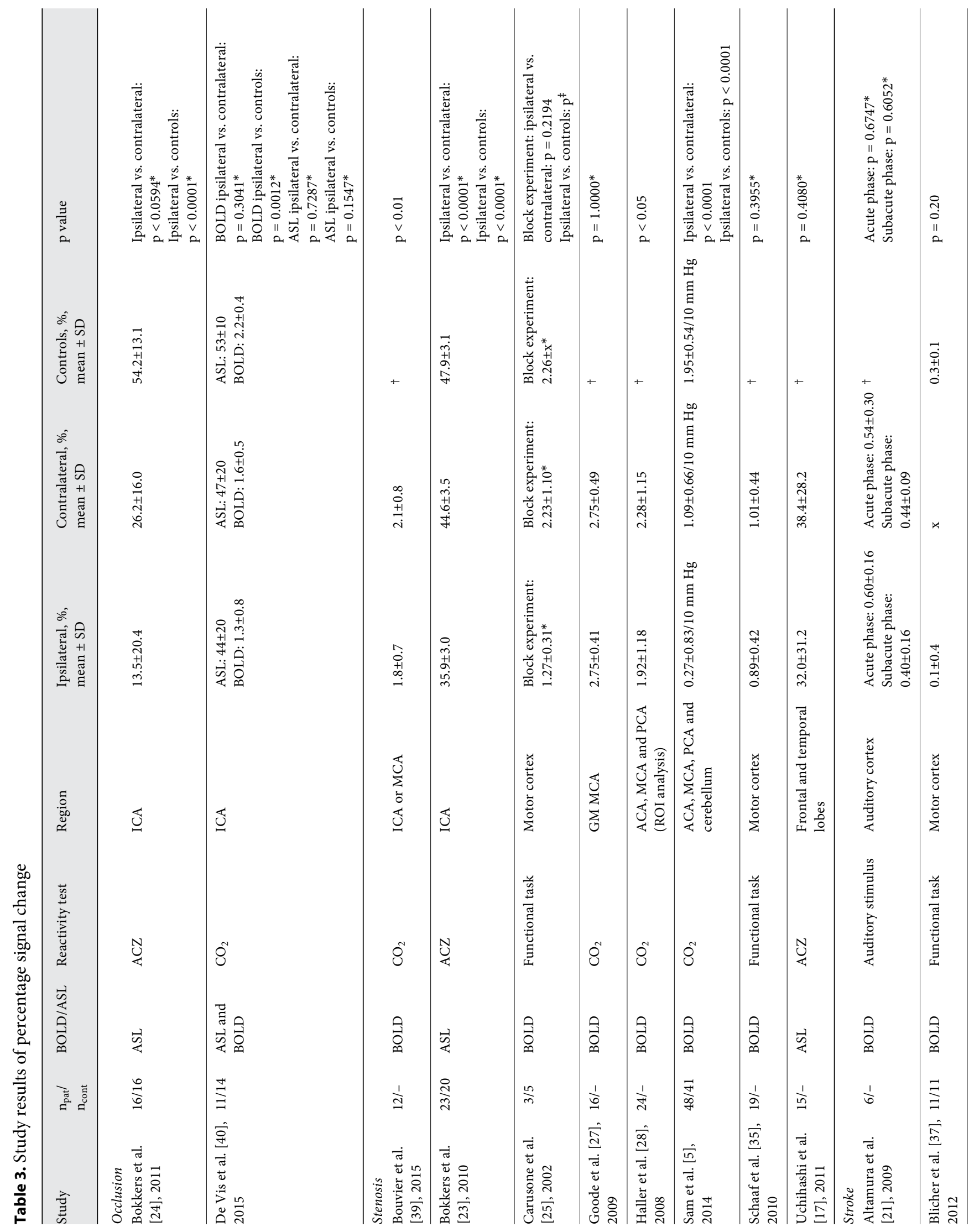




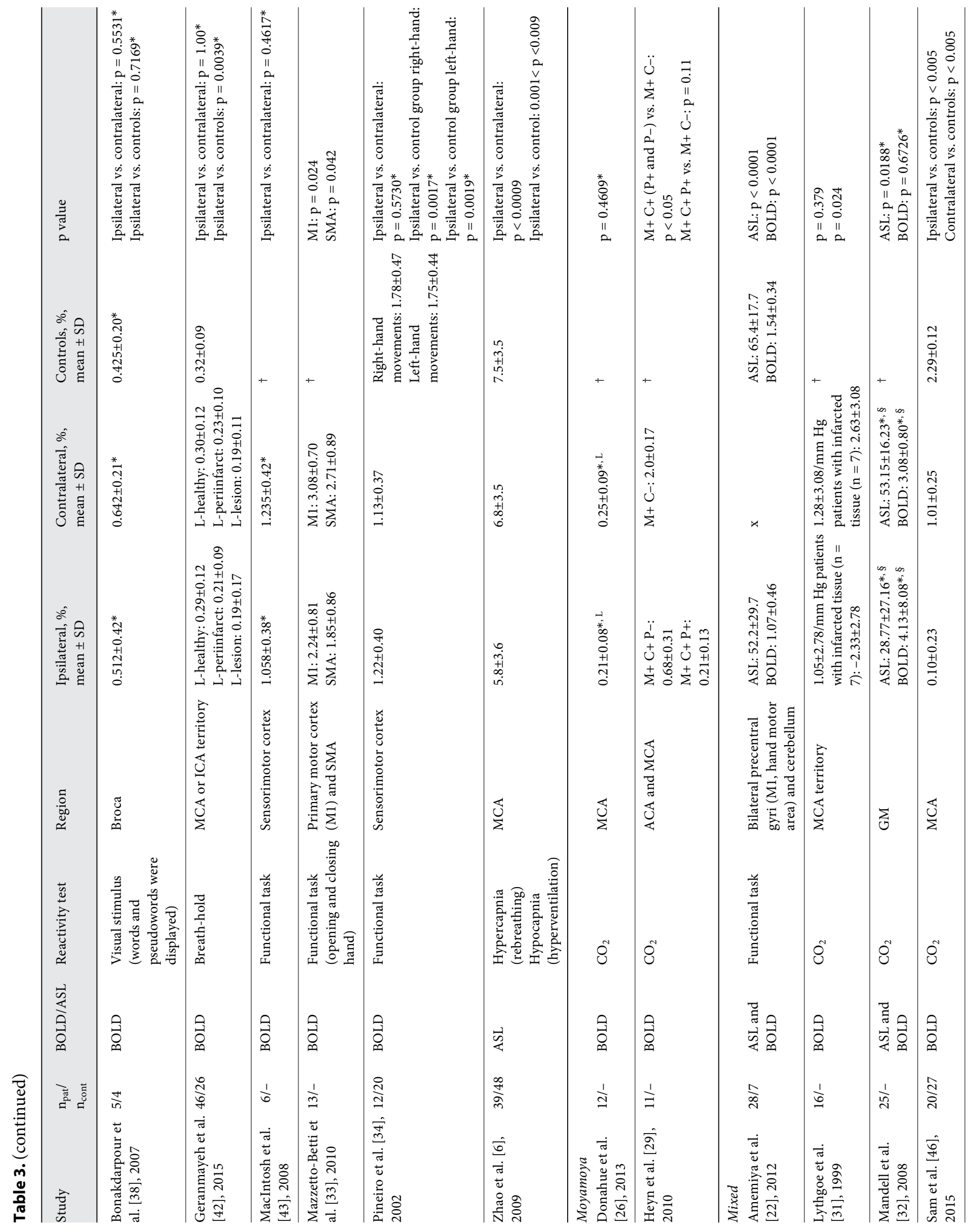




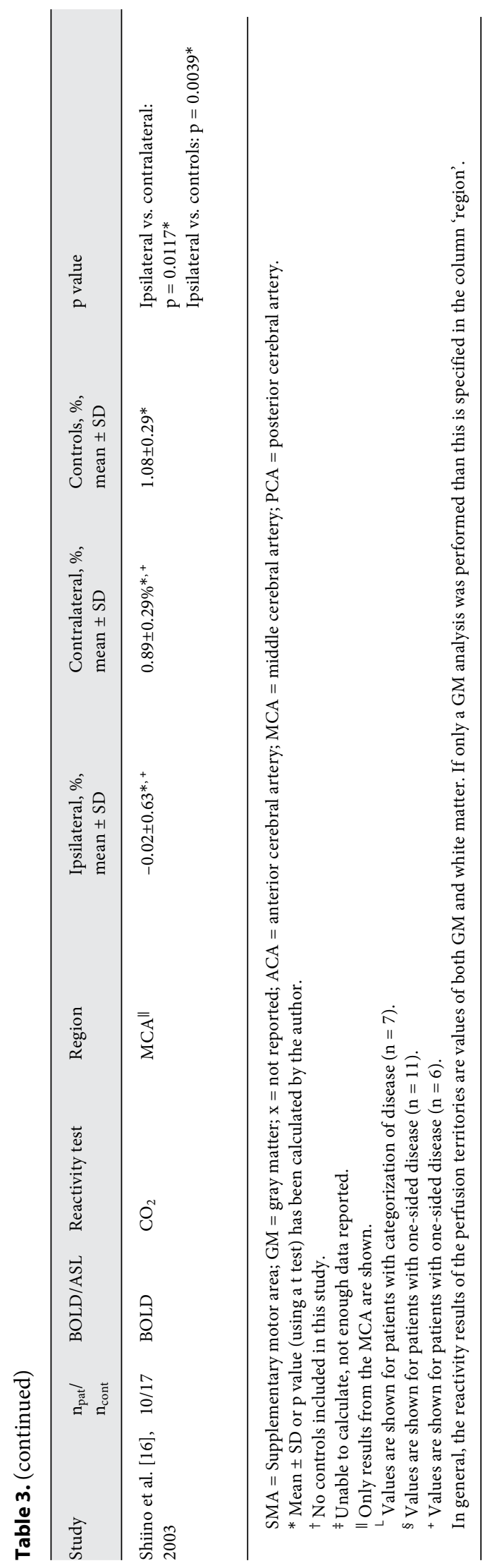

ipsilateral compared to the contralateral hemispheres, 2 of these studies found a significant difference $[6,17,23$, $24,32,40]$. Five studies compared the ASL CVR results of patients to the ASL CVR results of a healthy control group and found a lower ASL CVR in the ipsilateral hemispheres of the patients compared to the ASL CVR measured within the healthy control group $[6,22-24,40]$. Three of these studies found significant differences. No study found an equal or higher ASL CVR ipsilaterally compared to contralaterally, or, equal or higher ASL CVR in the patients compared to the controls.

\section{Subgroup Analyses}

In the BOLD studies, subgroup analyses demonstrated a significantly lower BOLD CVR in the ipsilateral hemispheres of studies who included patients with stenosis $(n=5)$ or included a mixed group of patients $(n=4$; fig. 6). Subgroup analyses in the stroke studies $(n=3)$ and in the MMD studies $(\mathrm{n}=2)$ did not demonstrate significant differences.

Subgroup analyses were not performed for the included ASL studies because only 7 studies could be included; this in turn led to too low numbers in the subgroups. The $\mathrm{I}^{2}$ value for heterogeneity was $97 \%$, which shows a high heterogeneity. The results from heterogeneity tests for the different subgroups are shown in figure 6.

\section{Safety Analyses}

A solid safety analysis was performed in one of the included papers, and they reported claustrophobia in $1.6 \%$. More importantly, within this study, no stroke-like symptoms outside the range of what should be expected were found [7]. One group reported anxiety evoked by hypercapnic breathing in $13 \%$ of their patients, and Bouvier et al. [39] reported discomfort due to the face mask in $9 \%$ of the patients [40].

\section{Discussion}

For the first time, this review groups the results of BOLD and ASL CVR measurements in cerebrovascular disease and thereby gives a comprehensive overview of the BOLD and ASL CVR data present in the literature. Overall, as expected, the results presented in this systematic review bring support for a reduced BOLD and ASL CVR in the ipsilateral hemisphere of patients with stenoocclusive cerebrovascular disease. When combining the BOLD CVR results of all studies concerning patients 


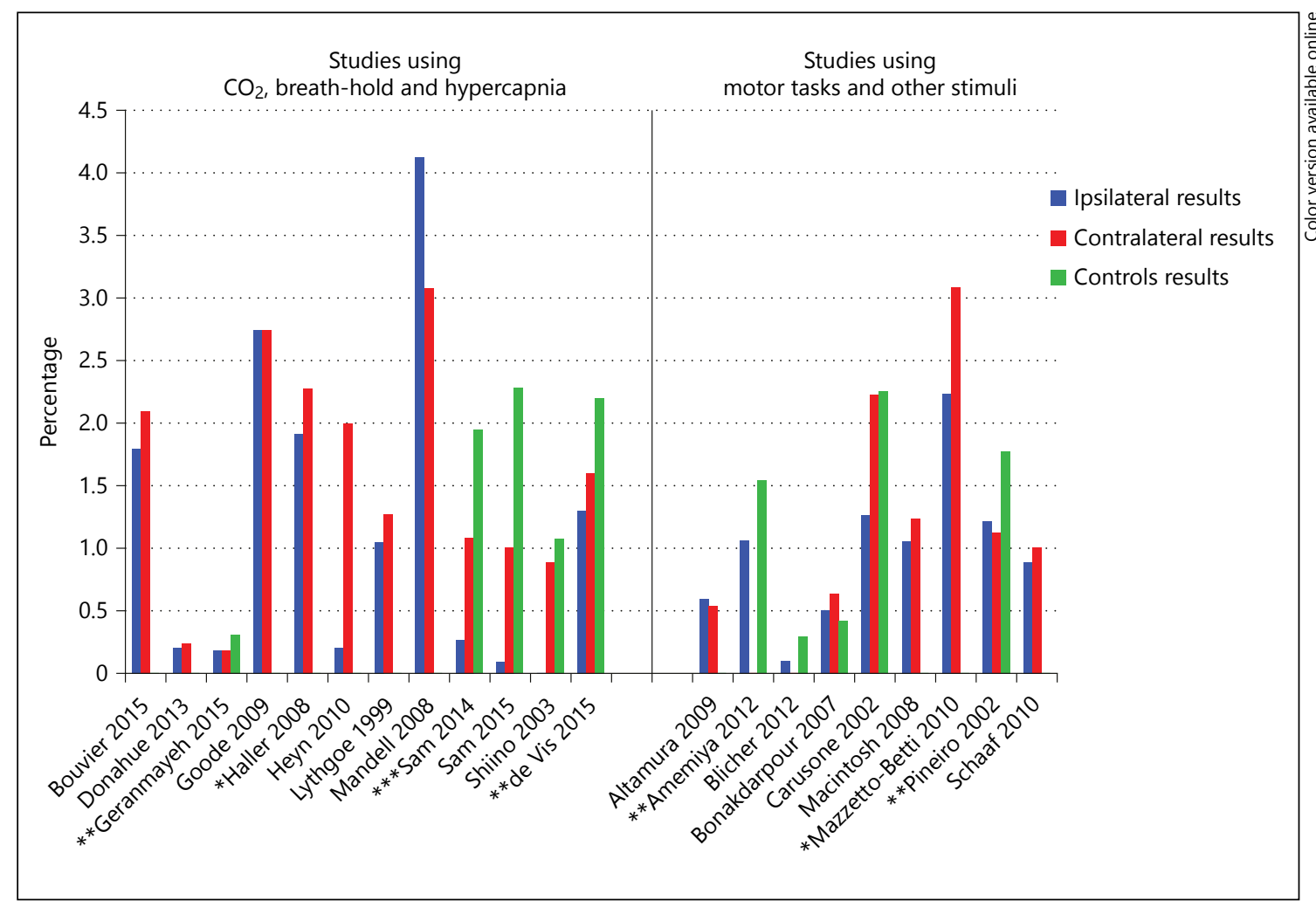

Fig. 4. Results of the BOLD CVR MRI studies. * Ipsilateral vs. contralateral results are significant ( $\mathrm{p}$ value $<0.05$ ). ${ }^{* *}$ Ipsilateral vs. controls results are significant ( $\mathrm{p}$ value $<0.05)$. ${ }^{* * *}$ Ipsilateral vs. contralateral results and ipsilateral vs. controls are significant $(\mathrm{p}$ value $<0.05$ ). The low \%BOLD CVR in Donahue et al. [26] and Geranmayeh et al. [42] are caused by normalization of the \%BOLD CVR changes by the end-tidal $\mathrm{CO}_{2}$.
Fig. 5. Results of the ASL CVR MRI studies. * Ipsilateral vs. contralateral results are significant ( $p$ value $<0.05$ ). ${ }^{* *}$ Ipsilateral vs. controls results are significant ( $\mathrm{p}$ value $<0.05)$. ${ }^{* * *}$ Ipsilateral vs. contralateral results and ipsilateral vs. controls are significant ( $\mathrm{p}$ value $<0.05$ ).

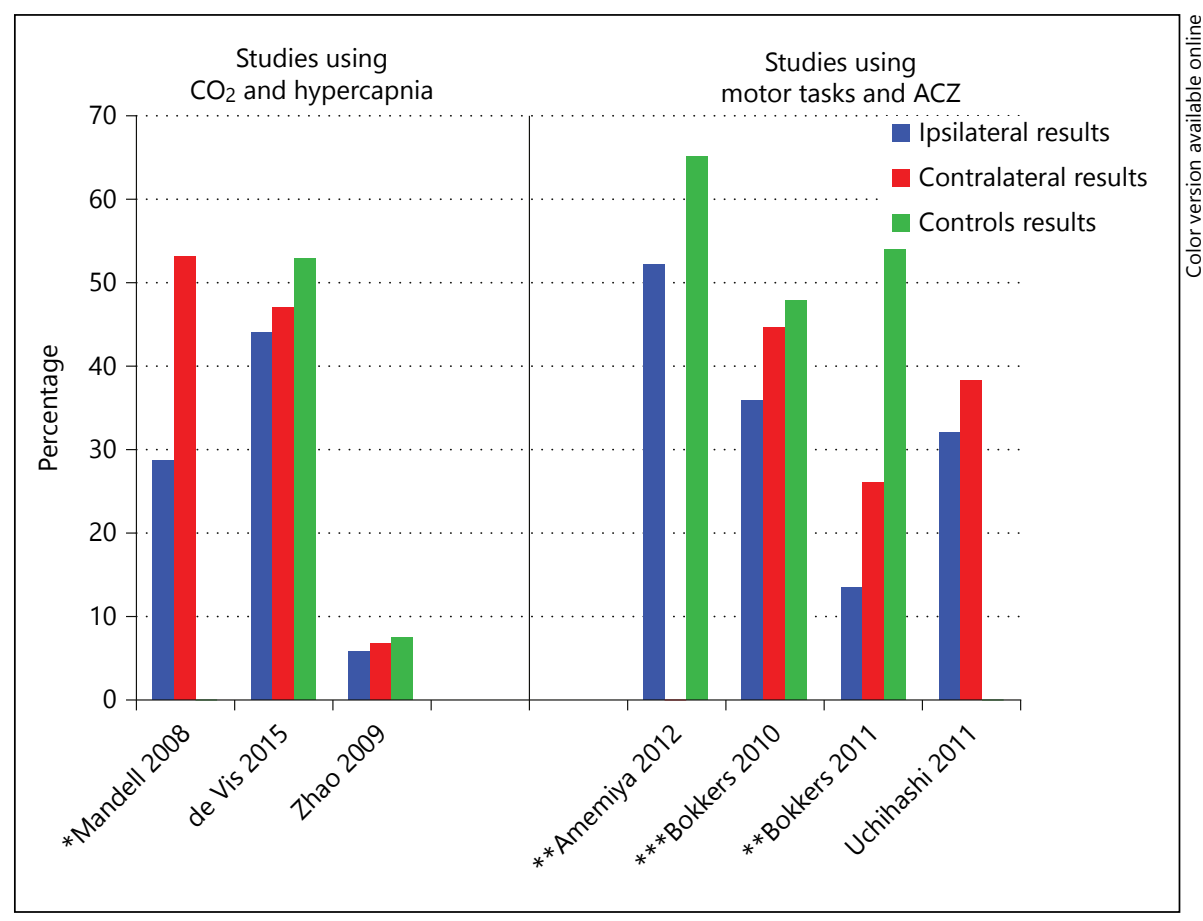




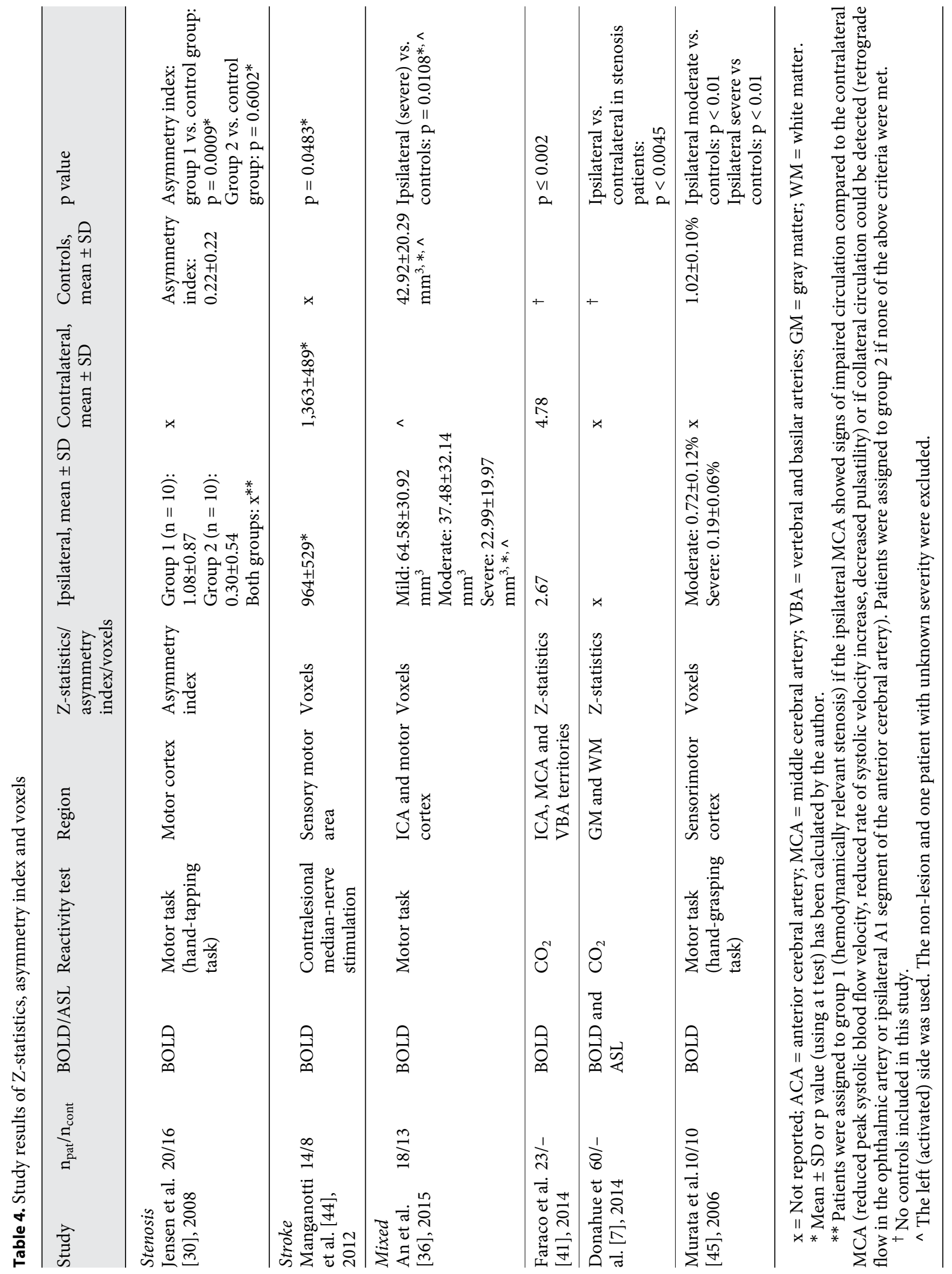




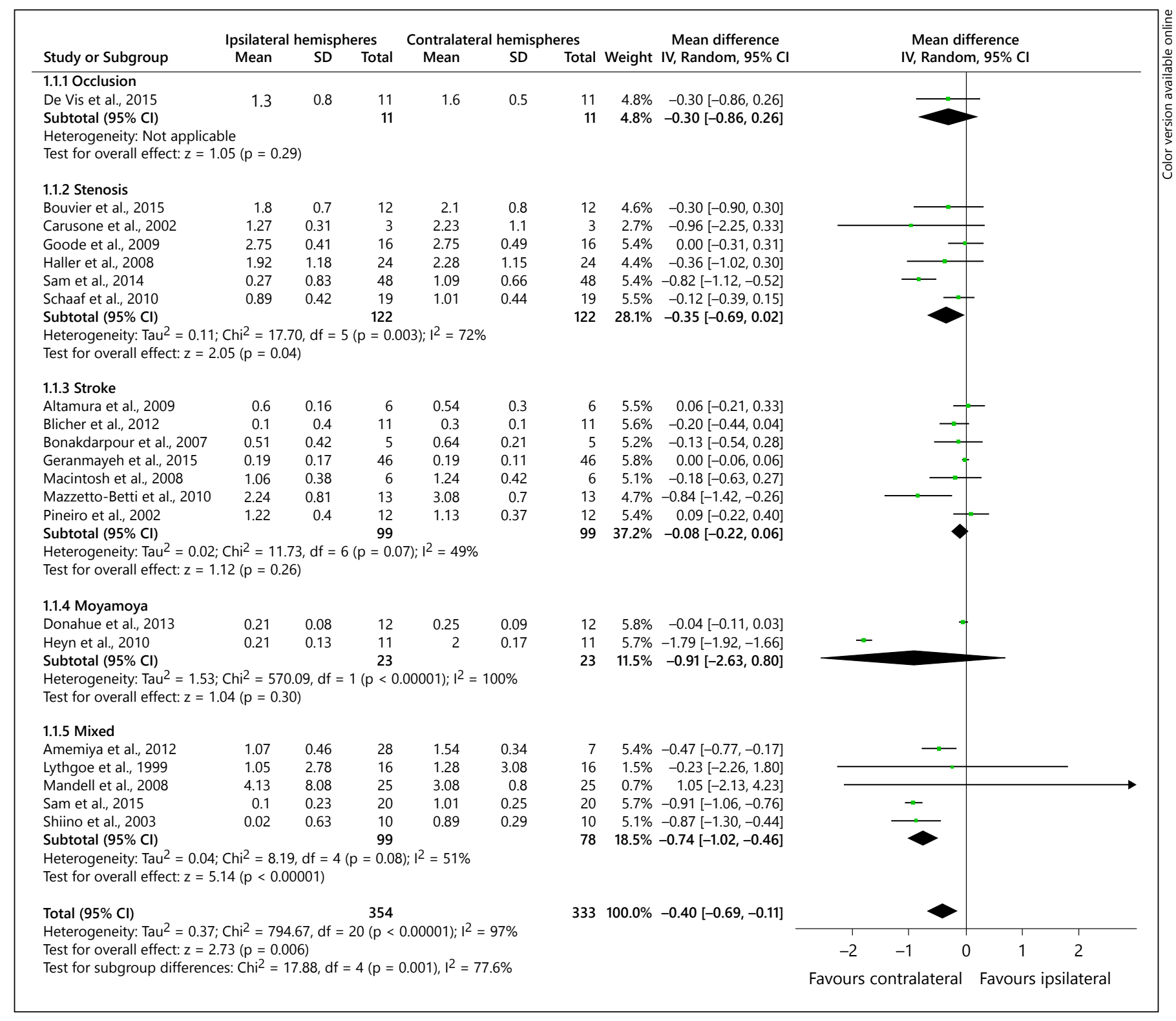

Fig. 6. Subgroup analyses of the BOLD CVR MRI studies.

with stenosis, a significant lower BOLD CVR was found in the ipsilateral compared to the contralateral hemispheres (MD $-0.35 ; 95 \% \mathrm{CI}-0.69$ to -0.02 ), similar to the instance when the data of a mixed group of patients were grouped (MD $-0.74 ; 95 \% \mathrm{CI}-1.02$ to -0.46 ). From the figures presented in the manuscript, a large variability in CVR results can be appreciated. This variability is most likely caused by methodological as well as clinical diversity and precludes providing BOLD and ASL CVR reference values in presumably poorly perfused and healthy tissue.

ASL and BOLD MRI CVR in

Cerebrovascular Disease

\section{BOLD and ASL CVR Results in Cerebrovascular}

Disease

A majority of the BOLD and ASL CVR studies found a significant lower CVR in the ipsilateral compared to the contralateral hemisphere. Still, 3 studies using BOLD MRI showed a higher, though not significant, BOLD CVR in the ipsilateral compared to the contralateral hemispheres $[21,32,34]$. One of them was the study of Mandell et al. [32] who found a BOLD CVR of $4.13 \pm$ $8.08 \%$ in the ipsilateral and $3.08 \pm 0.80 \%$ in the contralateral hemisphere. Though, when scrutinizing their data 
we noticed an outlier within their results (case number 25; BOLD CVR ipsilateral: $2.82 \%$ and contralateral: $0.33 \%)$. This outlier skewed their BOLD results, and in fact, when the results of this case were not included in the analyses, the results were the opposite: the ipsilateral hemispheres than had a lower CVR compared to the contralateral hemispheres (ipsilateral: $1.27 \pm 1.28 \%$; contralateral: $3.06 \pm 0.84 \%)$. This outlier may be caused by an error in their BOLD measurement as they did find lower ASL CVR in the ipsilateral compared to the contralateral hemisphere of this subject (ipsilateral: $0.30 \%$ and contralateral: $5.27 \%$ ). Another study that found higher BOLD CVR in the ipsilateral hemisphere was the study of Pineiro et al. [34] (ipsilateral: $1.22 \pm 0.40 \%$; contralateral: $1.13 \pm 0.37 \%)$. In their discussion, the higher BOLD CVR response on the ipsilateral side was attributed to an increased ipsilateral blood flow and blood volume as a consequence of increased synaptic activity. However, it should be noticed that the difference in results between ipsilateral and contralateral hemispheres were only minor and insignificant. Also, they did find a lower BOLD CVR in the ipsilateral hemisphere of patients compared to the controls. The third and last study, which found a higher CVR ipsilaterally, was the study by Altamura et al. [21] who attributed this to the decreased fMRI signal detection in hemodynamic impaired patients resulting in more noise within the data. A reason as to why studies could find a higher CVR ipsilaterally could be cerebral metabolic rate of oxygen $\left(\mathrm{CMRO}_{2}\right)$ upregulation in the ipsilateral hemisphere [48]. $\mathrm{CMRO}_{2}$ upregulation can be caused by a hypercarbic hyperoxia stimulus (carbogen) in which the tissue that is hypoxic at baseline metabolizes the additional oxygen provided and therefore artificially decreases the relative amount of $\mathrm{dHb}$ being present, thus creating a falsely increased CVR. In essence, this would mean that an increased CVR is a surrogate marker of impaired $\mathrm{CMRO}_{2}[49,50]$. However, this could be confirmed only when BOLD CVR measurements are combined with $\mathrm{CBF} / \mathrm{CBV}$ measurements. Another reason for a higher CVR in the ipsilateral hemisphere could be the baseline vasodilation status of poorly perfused tissue. This hypothesis finds support in the enhanced hypocapnia reactivity observed within stroke patients [6]. Therefore, additional hypocapnia challenges may help identify the level of vascular compliance in patients with reduced cerebral perfusion [51]. Something to take into account when interpreting the studies who found a higher CVR ipsilaterally is that 2 out of the 3 studies applied a functional task or an auditory stimulus $[21,34]$. This makes the interpretation of the increased BOLD re- sponses in light of cerebrovascular disease much more complex due to task-induced changes in neurovascular coupling, $\mathrm{CMRO}_{2}$ and other confounding factors [52, 53].

\section{The Effect of Time Window after Stroke Onset}

As described previously, the studies performed in stroke patients were performed at different time intervals after stroke onset and thereby introduce clinical diversity in this systematic review. The evolution of the CVR after stroke has not been investigated thoroughly so far, though we did include one paper that measured the CVR both in the acute and subacute stroke phases. In this paper, a higher BOLD CVR in the ipsilateral hemispheres in the acute phase (ipsilateral: $0.60 \pm 0.16 \%$; contralateral: $0.54 \pm 0.30 \%$ ) compared to the subacute phase (ipsilateral: $0.40 \pm 0.16 \%$; contralateral: $0.44 \pm 0.09 \%)$ was found [21]. This was thought to originate from an increase in the time to peak latency, that is, the time that it takes for the BOLD signal to reach its maximum signal change after the initiation of the stimulus, when patients advance from the acute to the subacute phase [21]. If this would in fact be the case, then these differences would be overcome by discarding the images acquired during the latency period.

\section{Inter-Trial Variability}

A second important finding of this review is that there is wide variability within the obtained BOLD and ASL CVR measurements. The BOLD CVR measurements ipsilaterally ranged from -0.02 to $4.13 \%$, the contralateral results ranged from 0.19 to $3.08 \%$, and the controls ranged from 0.3 to $2.29 \%$. The ipsilateral results in ASL MRI ranged from 5.8 to $52.2 \%$, the contralateral results ranged from 6.8 to $53.15 \%$, and the controls ranged from 7.5 to $65.4 \%$. This finding might correlate with the fact that there is no universally defined manner to measure the CVR in combination with a nonuniform way of presenting the results. Apart from this wide variability, one can also notice that there is a considerable overlap between the different groups presented in the different papers. For example, the patients in the study of Goode et al. [27] have BOLD values in a similar range in their ipsilateral hemisphere as the CVR values found in the contralateral hemispheres of the study of Mazzetto-Betti et al. [33] or Mandell et al. [32]. Despite this overlap, there seems to be a trend toward higher CVR values from the ipsilateral to the contralateral hemisphere and to the control hemispheres. The variability in BOLD and ASL values are multifactorial. The variability in measure- 
ments can be explained both by clinical and methodological diversity.

Methodological diversity is introduced by differences in sequences and post-processing algorithms in between vendors and research groups, differences in the field strength of the magnet, and differences in vasodilatory stimuli as well as timing of imaging after administration of the vasodilatory stimulus. One of these differences in between sequences is the postlabel delay, which is used in ASL MRI and ranged from 1,000 to 2,500 $\mathrm{ms}$ in the included studies $[22,32]$. When a shorter postlabel delay is used, the label may still be present in the vasculature at the time of imaging, causing an overestimation of the $\mathrm{CBF}$ and based on the results found in the presented studies, as well from the CVR $[32,54]$. This is specifically important within the investigated population as subjects with cerebrovascular disease are known to have longer arterial transit times compared to healthy controls and are thus more prone to an overestimation when too short of a postlabel delay is used [55]. Ideally the postlabel delay would have been adjusted on an individual basis by determining the subject's transit time using for instance a look-locker readout [56]. This would have made the comparison between patients and healthy controls more accurate, although it would demand more imaging time, which is not always possible. A second major contributor to methodological diversity is the impact of MRI field strength on signal-to-noise ratio (SNR). Both BOLD and ASL MRI benefit from higher SNR and therefore study results could significantly differ depending on field strength. From the studies included in this systematic review, 8 studies were performed on $1.5 \mathrm{~T}$ and 22 studies on $3 \mathrm{~T}$ and no big differences were found in their study results. Another difference that can cause wide variability in the measurements is the vasodilatory challenge itself. Different functional tasks, different doses of ACZ, different timing of imaging after ACZ administration, differences in hypercapnia level and different breath-hold techniques were used causing different CVR responses [57]. Specifically from breath-holding it is known to cause varying outcome among individuals due to subject-physiology and the fact that not all patients can hold their breath as long [58]. Also, even when a similar $\mathrm{CO}_{2}$ or carbogen level is administered to the patient, interindividual differences will arise based on differences in respiratory rate and ventilation volume. Ideally, the hypercapnia challenge would be based on $\mathrm{EtCO}_{2}$ measurements to guarantee a similar challenge in all subjects. Another factor that has to be taken into account is that a hypercapnic challenge not only affects flow amount but also decreases arterial transit time by increasing flow velocity $[59,60]$. In case of decreased or stagnant flow at baseline, which is common in patients with cerebrovascular disease, changes in arterial transit time can confound CVR measurements. This could be problematic as CVR is most likely to be overestimated and thus will induce systematic errors. Another remark is that blood $T_{1}$ is affected by carbogen and this could impact CBF quantification in ASL-based CVR studies [61]. The BOLD signal is a complex outcome of flow and metabolism, which may both change during a hypercapnic stimulus, and thereby make BOLD CVR less interpretable in the sense of pathophysiology [60, 62, 63]. Additionally, functional tasks are known to alter neurovascular coupling with an unequal increase in both CBF as in $\mathrm{CMRO}_{2}$ which results in the outcome that a functional task cannot be considered a true CVR measurement [64-66]. Nevertheless, we did decide to include these studies as they are commonly used due to their ease of implementation as compared to other vasodilatory stimuli. However, we do want to point out that out of the 7 studies with significant differences in BOLD CVR between the ipsilateral and contralateral hemisphere, 3 studies applied a functional task [22, 33, 34]. In addition to these studies not necessarily reflecting 'pure' CVR, their study results could also have been affected by poor task performance of the subjects.

Clinical diversity is introduced by differences in timing of imaging after onset of the disease, differences in stenosis grade as shown in table 2 , heterogeneous physiologic baseline conditions such as baseline brain metabolism and quantities such as hematocrit, which is known to influence the $\mathrm{T}_{1}$ of blood $[67,68]$. Thus far, all of these technique-related differences refrain us from obtaining BOLD and ASL CVR reference values for normal and abnormal perfused brain tissue.

\section{Clinical Applicability and Safety Aspects}

The advantage of BOLD and ASL CVR MRI measurements, as compared to the earlier performed PET and SPECT CVR measurements, is their noninvasiveness characteristic. To be clinically applicable, the techniques should also be clinically feasible, patient friendly and safe. So far, this latter issue has not been investigated thoroughly, as most of the studies covered within this review did not provide information of adverse events or side effects. Based on the studies that provide this information, we can deduce that in general, the CVR measurements seem to be safe and reasonably tolerable making it appropriate to be used in clinical practice. This was confirmed 
in a large cohort study which applied a prospectively targeted hypercapnia stimulus in 434 patients and found this to be safe [69].

\section{Strengths and Limitations}

The strength of this systematic review is that it systematically presents the results of BOLD and ASL CVR studies performed so far in patients with cerebrovascular disease. This allows interested clinicians or researchers working within this field to get a comprehensive overview of the available data. A previously published review did look into the BOLD and ASL CVR MRI studies performed in carotid steno-occlusive disease, but they did not provide a systematic overview of the resulting BOLD and ASL CVR results [70]. Also, in our review, data are presented for different subgroups of cerebrovascular disease: stroke, stenosis, occlusion and MMD respectively. Likewise, clinical diversity is present in this review as studies included different groups of patients (occlusion, stenosis, stroke and moyamoya). In figure 6 , a subgroup analysis has been performed to see if a subgroup showed contrary results compared to other groups, which was not the case. However, this could have been expected in advance due to large heterogeneity based on the clinical and methodological diversity mentioned earlier.

Unfortunately, most of the studies included in this paper scored intermediate on the quality assessment, mainly due to their sample size. A potential limitation of this review is that we limited our search to quantitative studies, thereby restricting the amount of included papers. The reason as to why we choose to only include quantitative studies is that these study results have the potential to be compared. Also, a previous study demonstrated that a quantitative decrease in CVR is a better predictor of recurrent stroke than a qualitative decrease [3]. This was confirmed by Yokota et al. [71] who showed that a qualitative change was not a significant independent predictor in stroke patients with occlusive large-artery disease. However, the inclusion of only quantitative studies could have led to publication bias in our results. A thorough investigation of publication bias could not be performed in this review, as this would require similar functional tasks in all included studies. It is known that the effect of $\mathrm{ACZ}, \mathrm{CO}_{2}$ and functional tasks on the obtained CVR differs.

Another limitation of this review is that the patient characteristics of the presented studies are not fully comparable. As described in the section 'inter-trial variability', disadvantages of the current literature on BOLD and ASL CVR data are the unstandardized vasodilatory methods, different BOLD and ASL MRI sequences and differ- ent post-processing techniques. This is reflected in the high heterogeneity, which was found in the studies included in the subgroup analyses.

\section{Future Directions}

Although BOLD and ASL CVR measurements hold great promise, the absence of reference values is the largest obstacle that needs to be overcome before applying these noninvasive, and thus high-potential, techniques in daily clinical care. In this context, it is worth mentioning the effort performed by Sobczyk et al. [72] who generated a BOLD CVR reference atlas and even demonstrated this one to be useful to detect abnormal BOLD CVR values [73]. However, in order to make full use of such a reference atlas across centers, there is a need to identify a uniform stimulus and standardize the quantification procedure. Also, in order to adopt CVR measurements in clinical practice, future studies should consistently report adverse events and safety. Once standardized protocols, for both sequences and vasodilatory challenges, are achieved, new studies should be performed to obtain reference CVR values both in the healthy and the diseased. Prospective studies investigating the relation between CVR and stroke risk should be started. These studies could then be used to establish reference values that would enable us to identify the hemodynamically impaired patients. Because, even though recent trials were halted, as they did not find benefit of surgery over best medical care, it could be that surgery increases survival risk in those patients who are hemodynamically impaired the most [7376]. Treatment decisions could thus be based on both CVR results and the clinical symptoms, and selected patients could be offered additional treatment [77].

\section{Conclusion}

This review gives, for the first time, an overview of all the quantitative study results of CVR measurements performed in patients with cerebrovascular disease or stroke. As expected, the results support a reduced CVR in the ipsilateral hemisphere of patients with steno-occlusive cerebrovascular disease or stroke. However, the main accomplishment of this review is that it maps the variability within the obtained results, which is caused by nonuniformity of the performed studies. Therefore, we suggest that future studies will be performed in a uniform way so that reference values for poorly perfused and healthy brain tissue are established and could be used to guide treatment decisions in patients with cerebrovascular disease. 


\section{Acknowledgment/Disclosure Statement}

All authors declare they have no commercial associations that might pose a conflict of interest in connection with the submitted manuscript. This work was supported by the Netherlands Organization for Scientific Research (NWO) under grant number 91712322 (J.H.), the European Research Council under grant agreements number 637024 (J.H.).

\section{Authors Contribution}

D.P.J.S., J.B.V. and J.H. conceived and designed the experiments. D.P.J.S. and J.B.V. performed the experiments. D.P.J.S. analyzed the data. All authors critically reviewed the article and contributed to obtain the data needed.

\section{References}

1 Derdeyn CP, Grubb RL Jr, Powers WJ: Cerebral hemodynamic impairment: methods of measurement and association with stroke risk. Neurology 1999;53:251-259.

2 Kuroda S, Houkin K, Ishikawa T, Nakayama N, Iwasaki Y: Novel bypass surgery for moyamoya disease using pericranial flap: its impacts on cerebral hemodynamics and long-term outcome. Neurosurgery 2010;66:1093-1101.

3 Ogasawara K, Ogawa A, Terasaki K, Shimizu $\mathrm{H}$, Tominaga T, Yoshimoto T: Use of cerebrovascular reactivity in patients with symptomatic major cerebral artery occlusion to predict 5-year outcome: comparison of xenon-133 and iodine-123-IMP single-photon emission computed tomography. J Cereb Blood Flow Metab 2002;22:1142-1148.

4 Yamashita T, Urakawa M, Yasuda H, Matayoshi Y: Measurement of cerebral reserve capacity using acetazolamide loading xenon CT CBF before carotid endarterectomy. J Neuroradiol 2005;32:329-331.

5 Sam K, Small E, Poublanc J, Han JS, Mandell DM, Fisher JA, et al: Reduced contralateral cerebrovascular reserve in patients with unilateral steno-occlusive disease. Cerebrovasc Dis 2014;38:94-100.

6 Zhao P, Alsop DC, Abduljalil A, Selim M, Lipsitz L, Novak P, et al: Vasoreactivity and periinfarct hyperintensities in stroke. Neurology 2009;72:643-649.

7 Donahue MJ, Dethrage LM, Faraco CC, Jordan LC, Clemmons P, Singer R, et al: Routine clinical evaluation of cerebrovascular reserve capacity using carbogen in patients with intracranial stenosis. Stroke 2014;45:2335-2341.

8 Yezhuvath US, Lewis-Amezcua K, Varghese $\mathrm{R}, \mathrm{Xiao} \mathrm{G}, \mathrm{Lu} \mathrm{H}$ : On the assessment of cerebrovascular reactivity using hypercapnia BOLD MRI. NMR Biomed 2009;22:779-786.

9 Sullivan HG, Kingsbury TB 4th, Morgan ME, Jeffcoat RD, Allison JD, Goode JJ, et al: The rCBF response to Diamox in normal subjects and cerebrovascular disease patients. J Neurosurg 1987;67:525-534.

10 Noguchi T, Kawashima M, Irie H, Ootsuka T, Nishihara M, Matsushima T, et al: Arterial spin-labeling MR imaging in moyamoya disease compared with SPECT imaging. Eur J Radiol 2011;80:e557-e562.

11 Fluck D, Beaudin AE, Steinback CD, Kumarpillai G, Shobha N, McCreary CR, et al: Effects of aging on the association between cerebrovascular responses to visual stimulation, hypercapnia and arterial stiffness. Front Physiol 2014;5:49.

12 Robertson JW, Debert CT, Frayne R, Poulin MJ: Variability of middle cerebral artery blood flow with hypercapnia in women. U1trasound Med Biol 2008;34:730-740.

13 Valdueza JM, Draganski B, Hoffmann O, Dirnagl U, Einhaupl KM: Analysis of CO2 vasomotor reactivity and vessel diameter changes by simultaneous venous and arterial Doppler recordings. Stroke 1999;30:81-86.

14 Claassen JA, Zhang R, Fu Q, Witkowski S, Levine BD: Transcranial Doppler estimation of cerebral blood flow and cerebrovascular conductance during modified rebreathing. J Appl Physiol (1985) 2007;102:870-877.

15 Heijtel DF, Mutsaerts HJ, Bakker E, Schober P, Stevens MF, Petersen ET, et al: Accuracy and precision of pseudo-continuous arterial spin labeling perfusion during baseline and hypercapnia: a head-to-head comparison with ${ }^{15} \mathrm{O}_{2} \mathrm{O}$ positron emission tomography. Neuroimage 2014;92:182-192.

16 Shiino A, Morita Y, Tsuji A, Maeda K, Ito R, Furukawa A, et al: Estimation of cerebral perfusion reserve by blood oxygenation level-dependent imaging: comparison with singlephoton emission computed tomography. J Cereb Blood Flow Metab 2003;23:121-135.

17 Uchihashi Y, Hosoda K, Zimine I, Fujita A, Fujii M, Sugimura K, et al: Clinical application of arterial spin-labeling MR imaging in patients with carotid stenosis: quantitative comparative study with single-photon emission CT. AJNR Am J Neuroradiol 2011;32: 1545-1551.

18 Ogawa S, Lee TM, Barrere B: The sensitivity of magnetic resonance image signals of a rat brain to changes in the cerebral venous blood oxygenation. Magn Reson Med 1993;29:205210.

19 Moher D, Liberati A, Tetzlaff J, Altman DG; PRISMA Group: Preferred reporting items for systematic reviews and meta-analyses: the PRISMA statement. BMJ 2009;339:b2535.

20 de Rooij NK, Rinkel GJ, Dankbaar JW, Frijns CJ: Delayed cerebral ischemia after subarachnoid hemorrhage: a systematic review of clinical, laboratory, and radiological predictors. Stroke 2013;44:43-54.
21 Altamura C, Reinhard M, Vry MS, Kaller CP, Hamzei F, Vernieri F, et al: The longitudinal changes of BOLD response and cerebral hemodynamics from acute to subacute stroke. A fMRI and TCD study. BMC Neurosci 2009; 10:151.

22 Amemiya S, Kunimatsu A, Saito N, Ohtomo $\mathrm{K}$ : Impaired hemodynamic response in the ischemic brain assessed with BOLD fMRI. Neuroimage 2012;61:579-590.

23 Bokkers RP, van Osch MJ, van der Worp HB de Borst GJ, Mali WP, Hendrikse J: Symptomatic carotid artery stenosis: impairment of cerebral autoregulation measured at the brain tissue level with arterial spin-labeling MR imaging. Radiology 2010;256:201-208.

24 Bokkers RP, van Osch MJ, Klijn CJ, Kappelle LJ, Hendrikse J: Cerebrovascular reactivity within perfusion territories in patients with an internal carotid artery occlusion. J Neurol Neurosurg Psychiatry 2011;82:1011-1016.

25 Carusone LM, Srinivasan J, Gitelman DR, Mesulam MM, Parrish TB: Hemodynamic response changes in cerebrovascular disease: implications for functional MR imaging. AJNR Am J Neuroradiol 2002;23:1222-1228.

26 Donahue MJ, Ayad M, Moore R, van Osch M, Singer R, Clemmons P, et al: Relationships between hypercarbic reactivity, cerebral blood flow, and arterial circulation times in patients with moyamoya disease. J Magn Reson Imaging 2013;38:1129-1139.

27 Goode SD, Altaf N, Auer DP, MacSweeney ST: Carotid endarterectomy improves cerebrovascular reserve capacity preferentially in patients with preoperative impairment as indicated by asymmetric BOLD response to hypercapnia. Eur J Vasc Endovasc Surg 2009;38:546-551.

28 Haller S, Bonati LH, Rick J, Klarhofer M, Speck O, Lyrer PA, et al: Reduced cerebrovascular reserve at CO2 BOLD MR imaging is associated with increased risk of periinterventional ischemic lesions during carotid endarterectomy or stent placement: preliminary results. Radiology 2008;249:251-258.

29 Heyn C, Poublanc J, Crawley A, Mandell D, Han JS, Tymianski M, et al: Quantification of cerebrovascular reactivity by blood oxygen level-dependent MR imaging and correlation with conventional angiography in patients with moyamoya disease. AJNR Am J Neuroradiol 2010;31:862-867.
ASL and BOLD MRI CVR in

Cerebrovascular Disease
Cerebrovasc Dis 2016:42:288-307 
30 Jensen U, Borsch K, Stingele R, Jansen O, Alfke K: Hemodynamic assessment of carotid stenosis by functional magnetic resonance imaging. Cerebrovasc Dis 2008;26:231-236.

31 Lythgoe DJ, Williams SC, Cullinane M, Markus HS: Mapping of cerebrovascular reactivity using BOLD magnetic resonance imaging. Magn Reson Imaging 1999;17:495502.

32 Mandell DM, Han JS, Poublanc J, Crawley AP, Stainsby JA, Fisher JA, et al: Mapping cerebrovascular reactivity using blood oxygen level-dependent MRI in patients with arterial steno-occlusive disease: comparison with arterial spin labeling MRI. Stroke 2008;39: 2021-2028.

33 Mazzetto-Betti KC, Leoni RF, Pontes-Neto OM, Santos AC, Leite JP, Silva AC, et al: The stability of the blood oxygenation level-dependent functional MRI response to motor tasks is altered in patients with chronic ischemic stroke. Stroke 2010;41:1921-1926.

34 Pineiro R, Pendlebury S, Johansen-Berg H, Matthews PM: Altered hemodynamic responses in patients after subcortical stroke measured by functional MRI. Stroke 2002;33: 103-109.

35 Schaaf M, Mommertz G, Ludolph A, Geibprasert S, Muhlenbruch G, Das M, et al: Functional MR imaging in patients with carotid artery stenosis before and after revascularization. AJNR Am J Neuroradiol 2010;31:17911798.

36 An H, Rajeev O, Huang D, Yang J, Li J, Yu F, et al: Influence of internal carotid artery stenosis, blood pressure, glycated hemoglobin, and hemoglobin level on fMRI signals of stroke patients. Neurol Res 2015;37:502509.

37 Blicher JU, Stagg CJ, O’Shea J, Østergaard L, Macintosh BJ, Johansen-Berg H, et al: Visualization of altered neurovascular coupling in chronic stroke patients using multimodal functional MRI. J Cereb Blood Flow Metab 2012;32:2044-2054.

38 Bonakdarpour B, Parrish TB, Thompson CK: Hemodynamic response function in patients with stroke-induced aphasia: implications for fMRI data analysis. Neuroimage 2007;36: 322-331.

39 Bouvier J, Detante O, Tahon F, Attye A, Perret $\mathrm{T}$, Chechin D, et al: Reduced $\mathrm{CMRO}_{2}$ and cerebrovascular reserve in patients with severe intracranial arterial stenosis: a combined multiparametric $\mathrm{qBOLD}$ oxygenation and BOLD fMRI study. Hum Brain Mapp 2015; 36:695-706.

40 De Vis JB, Petersen ET, Bhogal A, Hartkamp NS, Klijn CJ, Kappelle LJ, et al: Calibrated MRI to evaluate cerebral hemodynamics in patients with an internal carotid artery occlusion. J Cereb Blood Flow Metab 2015;35: 1015-1023.

41 Faraco CC, Strother MK, Dethrage LM, Jordan L, Singer R, Clemmons PF, et al: Dual echo vessel-encoded ASL for simultaneous BOLD and CBF reactivity assessment in pa- tients with ischemic cerebrovascular disease. Magn Reson Med 2015;73:1579-1592.

42 Geranmayeh F, Wise RJ, Leech R, Murphy K: Measuring vascular reactivity with breathholds after stroke: a method to aid interpretation of group-level BOLD signal changes in longitudinal fMRI studies. Hum Brain Mapp 2015;36:1755-1771.

43 Macintosh BJ, McIlroy WE, Mraz R, Staines WR, Black SE, Graham SJ: Electrodermal recording and fMRI to inform sensorimotor recovery in stroke patients. Neurorehabil Neural Repair 2008;22:728-736.

44 Manganotti P, Storti SF, Formaggio E, Acler M, Zoccatelli G, Pizzini FB, et al: Effect of median-nerve electrical stimulation on BOLD activity in acute ischemic stroke patients. Clin Neurophysiol 2012;123:142-153.

45 Murata Y, Sakatani K, Hoshino T, Fujiwara N, Kano T, Nakamura S, et al: Effects of cerebral ischemia on evoked cerebral blood oxygenation responses and BOLD contrast functional MRI in stroke patients. Stroke 2006;37: 2514-2520.

46 Sam K, Poublanc J, Sobczyk O, Han JS, Battisti-Charbonney A, Mandell DM, et al: Assessing the effect of unilateral cerebral revascularisation on the vascular reactivity of the non-intervened hemisphere: a retrospective observational study. BMJ Open 2015; 5:e006014.

47 Mugikura S, Takahashi S, Higano S, Shirane R, Sakurai Y, Yamada S: Predominant involvement of ipsilateral anterior and posterior circulations in moyamoya disease. Stroke 2002;33:1497-1500.

48 Arteaga DF, Strother MK, Faraco CC, Jordan LC, Ladner TR, Dethrage LM, et al: The vascular steal phenomenon is an incomplete contributor to negative cerebrovascular reactivity in patients with symptomatic intracranial stenosis. J Cereb Blood Flow Metab 2014;34: 1453-1462.

49 Leenders KL, Perani D, Lammertsma AA, Heather JD, Buckingham P, Healy MJ, et al: Cerebral blood flow, blood volume and oxygen utilization. Normal values and effect of age. Brain 1990;113(pt 1):27-47.

50 Marchal G, Rioux P, Petit-Taboue MC, Sette G, Travere JM, Le Poec C, et al: Regional cerebral oxygen consumption, blood flow, and blood volume in healthy human aging. Arch Neurol 1992;49:1013-1020.

51 Bright MG, Donahue MJ, Duyn JH, Jezzard P, Bulte DP: The effect of basal vasodilation on hypercapnic and hypocapnic reactivity measured using magnetic resonance imaging. J Cereb Blood Flow Metab 2011;31:426-438.

52 Brown GG, Eyler Zorrilla LT, Georgy B, Kindermann SS, Wong EC, Buxton RB: BOLD and perfusion response to finger-thumb apposition after acetazolamide administration: differential relationship to global perfusion. J Cereb Blood Flow Metab 2003;23:829-837.

53 Siero JC, Hartkamp NS, Donahue MJ, Harteveld AA, Compter A, Petersen ET, et al: Neuronal activation induced BOLD and CBF re- sponses upon acetazolamide administration in patients with steno-occlusive artery disease. Neuroimage 2015;105:276-285.

54 Hartkamp NS, van Osch MJ, Kappelle J, Bokkers RP: Arterial spin labeling magnetic resonance perfusion imaging in cerebral ischemia. Curr Opin Neurol 2014;27:42-53.

55 Bokkers RP, van Laar PJ, van de Ven KC, Kapelle LJ, Klijn CJ, Hendrikse J: Arterial spinlabeling MR imaging measurements of timing parameters in patients with a carotid artery occlusion. AJNR Am J Neuroradiol 2008;29: 1698-1703.

56 Gunther M, Bock M, Schad LR: Arterial spin labeling in combination with a look-locker sampling strategy: inflow turbo-sampling EPI-FAIR (ITS-FAIR). Magn Reson Med 2001;46:974-984.

57 Hare HV, Germuska M, Kelly ME, Bulte DP: Comparison of $\mathrm{CO} 2$ in air versus carbogen for the measurement of cerebrovascular reactivity with magnetic resonance imaging. J Cereb Blood Flow Metab 2013;33:1799-1805.

58 Kannurpatti SS, Motes MA, Biswal BB, Rypma B: Assessment of unconstrained cerebrovascular reactivity marker for large age-range FMRI studies. PLoS One 2014;9:e88751.

59 Coverdale NS, Gati JS, Opalevych O, Perrotta A, Shoemaker JK: Cerebral blood flow velocity underestimates cerebral blood flow during modest hypercapnia and hypocapnia. J Appl Physiol (1985) 2014;117:1090-1096.

60 Donahue MJ, Faraco CC, Strother MK, Chappell MA, Rane S, Dethrage LM, et al: Bolus arrival time and cerebral blood flow responses to hypercarbia. J Cereb Blood Flow Metab 2014;34:1243-1252.

61 Siero JC, Strother MK, Faraco CC, Hoogduin $\mathrm{H}$, Hendrikse J, Donahue MJ: In vivo quantification of hyperoxic arterial blood water T1. NMR Biomed 2015;28:1518-1525.

62 Kety SS, Schmidt CF: The effects of altered arterial tensions of carbon dioxide and oxygen on cerebral blood flow and cerebral oxygen consumption of normal young men. J Clin Invest 1948;27:484-492.

63 Xu F, Uh J, Brier MR, Hart J Jr, Yezhuvath US, $\mathrm{Gu} \mathrm{H}$, et al: The influence of carbon dioxide on brain activity and metabolism in conscious humans. J Cereb Blood Flow Metab 2011;31: 58-67.

64 Davis TL, Kwong KK, Weisskoff RM, Rosen BR: Calibrated functional MRI: mapping the dynamics of oxidative metabolism. Proc Natl Acad Sci U S A 1998;95:1834-1839.

65 Gauthier CJ, Desjardins-Crepeau L, Madjar C, Bherer L, Hoge RD: Absolute quantification of resting oxygen metabolism and metabolic reactivity during functional activation using QUO2 MRI. Neuroimage 2012;63: 1353-1363.

66 Hoge RD, Atkinson J, Gill B, Crelier GR, Marrett S, Pike GB: Investigation of BOLD signal dependence on cerebral blood flow and oxygen consumption: the deoxyhemoglobin dilution model. Magn Reson Med 1999;42:849863. 
67 De Vis JB, Hendrikse J, Bhogal A, Adams A, Kappelle LJ, Petersen ET: Age-related changes in brain hemodynamics: a calibrated MRI study. Hum Brain Mapp 2015;36:3973-3987.

$68 \mathrm{Lu} \mathrm{H}$, Clingman C, Golay X, van Zijl PC: Determining the longitudinal relaxation time (T1) of blood at 3.0 tesla. Magn Reson Med 2004;52:679-682.

69 Spano VR, Mandell DM, Poublanc J, Sam K, Battisti-Charbonney A, Pucci O, et al: $\mathrm{CO} 2$ blood oxygen level-dependent MR mapping of cerebrovascular reserve in a clinical population: safety, tolerability, and technical feasibility. Radiology 2013;266:592-598.

70 Leoni RF, Mazzetto-Betti KC, Silva AC, Dos Santos AC, de Araujo DB, Leite JP, et al: Assessing cerebrovascular reactivity in carotid steno-occlusive disease using MRI BOLD and ASL techniques. Radiol Res Pract 2012;2012: 268483 .
71 Yokota C, Hasegawa Y, Minematsu K, Yamaguchi T: Effect of acetazolamide reactivity on [corrected] long-term outcome in patients with major cerebral artery occlusive diseases. Stroke 1998;29:640-644.

72 Sobczyk O, Battisti-Charbonney A, Poublanc J, Crawley AP, Sam K, Fierstra J, et al: Assessing cerebrovascular reactivity abnormality by comparison to a reference atlas. J Cereb Blood Flow Metab 2015;35:213-220.

73 Derdeyn CP, Chimowitz MI, Lynn MJ, Fiorella D, Turan TN, Janis LS, et al: Aggressive medical treatment with or without stenting in high-risk patients with intracranial artery stenosis (SAMMPRIS): the final results of a randomised trial. Lancet 2014;383:333-341.

74 Zaidat OO, Castonguay AC, Fitzsimmons BF, Woodward BK, Wang Z, Killer-Oberpfalzer $M$, et al: Design of the Vitesse intracranial stent study for ischemic therapy (VISSIT) trial in symptomatic intracranial stenosis. J Stroke Cerebrovasc Dis 2013;22:1131-1139.
75 Chang TY, Kuan WC, Huang KL, Chang CH Chang YJ, Wong HF, et al: Heterogeneous cerebral vasoreactivity dynamics in patients with carotid stenosis. PLoS One 2013;8:e76072.

76 Mandell DM, Han JS, Poublanc J, Crawley AP, Fierstra J, Tymianski M, et al: Quantitative measurement of cerebrovascular reactivity by blood oxygen level-dependent MR imaging in patients with intracranial stenosis: preoperative cerebrovascular reactivity predicts the effect of extracranial-intracranial bypass surgery. AJNR Am J Neuroradiol 2011;32:721-727.

77 Chang TY, Liu HL, Lee TH, Kuan WC, Chang $\mathrm{CH}, \mathrm{Wu} \mathrm{HC}$, et al: Change in cerebral perfusion after carotid angioplasty with stenting is related to cerebral vasoreactivity: a study using dynamic susceptibility-weighted contrast-enhanced MR imaging and functional MR imaging with a breath-holding paradigm. AJNR Am J Neuroradiol 2009;30:1330-1336. 